\title{
Papers
}

\section{Potential benefits and challenges of e-detailing in Europe}

Received (in revised form): 21st July, 2003

\section{Roger Heutschi}

graduated from the University of St Gallen, Switzerland, in 2001 and is a research assistant in the Competence Center Business Networking 2 at the University's Institute of Information Management. He performs academic research in the area of business networking where he is developing architectures and methods for realising IT-supported collaborative processes between enterprises.

\section{Christine Legner}

is Project Manager of the Competence Center Business Networking 2 at the Institute of Information Management, University of St Gallen, Switzerland. Her research focus is on collaborative business processes. Before joining the Institute of Information Management in 2002, she held a management position at SAP AG, Germany.

\section{Andreas Schiesser}

has wide business experience within the pharmaceutical industry, covering market research, product management and marketing management. He was a member of the management board of Roche in Switzerland before joining the Integrated Health Care Solution initiative of Roche Pharmaceuticals in order to create synergies in the development and marketing of diagnostics and pharmaceuticals. In his current position he is Head of Business Information Management.

\section{Vladimir Barak}

is Global Head of Sales and Marketing Information Management at Roche. In his position he is currently establishing a global IM function for sales and marketing focusing on global coordination, cross-site aspects and local support (customer relationship management, sales processes, e-business opportunities, internet). He is member of the Information Management Team of Roche's Pharmaceuticals Division.

\section{Hubert Österle}

is a professor at the University of St Gallen (HSG), where he founded the Institute of Information Management (IWI-HSG) and the research programme 'Business Engineering HSG' in 1989. As Chief Technology Officer of The Information Management Group (IMG AG) and Professor of Information Management, Professor Österle combines the latest results from the field of research with topical requirements from practice.

\section{Keywords challenges and potentials, customer web interaction, electronic detailing}

Abstract E-detailing, which is understood to mean an IT-supported sales dialogue via the internet, has mainly been an issue in the USA in the last few years, where it has been heavily pushed by service providers. Recently, Europe has also seen more and more pharmaceutical companies expanding their conventional pharmaceutical product marketing to include electronic channels for interacting with their customers. It has been shown, however, that the approaches and experience in the USA are not readily transferable to Europe: legal restrictions, more heterogeneous markets, the novelty of communication channels and a lack of platform providers make it harder for pharmaceutical companies to exploit the potential of e-detailing. The findings of a study conducted between summer 2002 and spring 2003 suggest that electronic opportunities for customer contact and interaction

Roger Heutschi University of St Gallen, Institute of Information Management, MüllerFriedberg-Str. 8, 9000 St Gallen, Switzerland.

Tel: + 41712243378 Fax: + 41712242777 e-mail:

roger.heutschi@unisg.ch should be embedded in a more comprehensive spectrum of services supporting customers in their daily processes, which goes beyond straightforward product promotion.

\section{METHOD AND OVERVIEW}

The findings presented in this article are based on comprehensive bibliography research and on a study conducted from summer 2002 to spring 2003 by the Competence Center for Business 
Networking 2 of the Institute of Information Management at the University of St Gallen, Switzerland. In accordance with PROMET BECS, ${ }^{1}$ a case study research method for business engineering projects developed at the Institute of Information Management, personal interviews were held with management representatives from international pharmaceutical companies. Participants in the study included European subsidiaries of Roche Pharma, Novartis Pharmaceuticals and three pharmaceutical companies of comparable size and international reach that chose to stay anonymous for competitive reasons. The interviews lasted about 90 minutes. The main elements in all interviews were:

- general information about the company

- perceived challenges in conventional detailing

- company's strategy concerning e-business and e-detailing

- perceived potential benefits and challenges of e-detailing.

The following additional topics were covered if an e-detailing project was planned or had already been conducted (in three out of five cases):

- organisational and technical implementation

- costs and benefits of the project

- project experiences and critical project success factors.

From four out of these five interviews, detailed case studies were written which were reviewed by the interviewees.

This paper is structured as follows. The next section promotes the adoption of new marketing channels for pharmaceutical companies by showing typical shortcomings of conventional detailing. A definition of e-detailing as well as an overview of common edetailing approaches in the USA are then offered. The transferability of these approaches to the European market is examined by discussing their potential benefits and challenges. The paper concludes by discussing managerial implications.

\section{CHALLENGES IN CONVENTIONAL DETAILING}

As in other sectors, the efforts of pharmaceutical companies to identify profitable customers and retain their loyalty come under the heading of customer relationship management (CRM). The most important marketing tool in the area of prescription drugs is detailing, where field sales staff call on doctors at their practices or at hospitals to promote the sale of their products. Measured as a percentage of total marketing expenditure in the pharmaceutical industry, the costs of detailing in the USA are estimated at between 45 per cent ${ }^{2}$ and 70 per cent. ${ }^{3}$ In Europe, that percentage is significantly higher as there is no direct-to-consumer marketing.

The number of pharmaceutical field sales staff has shown constant growth over the past few years, doubling in the USA, for example, to around 80,000 between 1995 and 2001. ${ }^{4}$ This has resulted in an increasing number of pharmaceutical representatives trying to market their products to doctors, which further aggravates the existing problems with detailing. While the underlying situation may be slightly different in Europe, pharmaceutical companies there are also looking for new ways of marketing their products to doctors due to several challenges in conventional detailing: ${ }^{5-7}$

- Limited opportunities for personal calls. Doctors are under increasing time pressure and make a limited amount of time available to see an ever growing number of sales representatives. In the USA, for example, only one in five visits to a doctor 
is successful. ${ }^{8}$ In some regions, the large distances involved restrict the number of personal calls which can be made to doctors.

- Large intervals between sales calls. The low visit frequency associated with the limited opportunities for personal calls mean that it may well be several months after the launch of new products that a pharmaceutical representative is able to present them to the doctor.

- Short call duration. In the USA, detailing visits last on average between three and four minutes; in Europe (UK) around nine minutes. ${ }^{9}$ These lengths of time are inadequate to provide a doctor with a comprehensive product presentation.

- High costs. High costs associated with travelling and waiting time mean that an effective hour of detailing time incurs costs of up to $\mathcal{E}^{625}$ in the $\mathrm{UK}^{10}$ and US $\$ 2,000$ in the USA. ${ }^{11}$

- Inadequate availability of on-the-spot information. When pharmaceutical representatives call on doctors they frequently have insufficient information material with them or lack the background knowledge to answer all the doctor's questions. While this may lead to useful follow-on contacts, it also means undesirable delays in the information flow or unnecessary extra work for the representative or call centre. In view of the fact that the content of details and the timing of their release are mainly decided by the marketing department or the pharmaceutical representative, the doctor has little opportunity to influence the information flow.

- Lack of differentiation from competitors. The large number of mergers and acquisitions in the pharmaceutical sector in recent years means that doctors frequently no longer know which corporation markets which products. At the same time, an ever increasing number of pharmaceutical representatives are presenting what are often similar products from different suppliers. This makes it all the more difficult for manufacturers to differentiate their products effectively from those of their competitors.
- Standardisation in communication. In the case of conventional detailing, the personality and knowledge of the pharmaceutical representative are of great significance. While these aspects constitute an advantage for detailing calls, they also make it difficult for the pharmaceutical companies to ensure that their marketing messages are communicated in the same way throughout the market.

- Tendency to classify the doctors visited incorrectly. Success measurement in field sales is usually based on visit targets pharmaceutical representatives categorise the doctors they look after according to their potential for prescribing drugs (A, B, $\mathrm{C}$ customers) and have to achieve a minimum number of visits per year for each category. As ' $\mathrm{C}$ ' doctors tend to be easier to visit, there is a tendency to classify them incorrectly. This leads to inefficiencies in sales and marketing activities.

\section{E-DETAILING APPROACHES}

\section{Definition of e-detailing}

E-detailing denotes the use of information technology (IT) for promotional activities which provide customers (doctors, medical staff and patients) with information on pharmaceutical products. The aim of edetailing is to provide electronic support for and/or extend the established practice within the pharmaceutical sector of calling on doctors to promote pharmaceutical products. E-detailing can include the use of electronic channels for customer interaction as well as electronic support for sales representatives in their detailing calls, for example by providing them with electronic detailing aids or presentation material.

\section{Forms of e-detailing}

In practice, different approaches to edetailing have developed, which can be distinguished on the one hand by the type of interaction used to communicate, and on the other by the means of communication used (see Figure 1). 


\begin{tabular}{|c|c|c|c|}
\hline & $\begin{array}{l}\text { Human-human } \\
\text { interaction }\end{array}$ & $\begin{array}{l}\text { Rule-based human- } \\
\text { machine interaction }\end{array}$ & $\begin{array}{l}\text { Static human- } \\
\text { machine interaction }\end{array}$ \\
\hline Internet PC & $\begin{array}{l}\text { - Video detailing } \\
\text { - Telephone co-browsing } \\
\text { - Chat, forum }\end{array}$ & - Interactive web programs & $\begin{array}{l}\text { - Mass e-mail } \\
\text { - Static electronic content }\end{array}$ \\
\hline Mobile devices & - Chat & $\begin{array}{l}\text { - Interactive programs } \\
\text { for mobile devices }\end{array}$ & $\begin{array}{l}\text { - Mobile device messaging } \\
\text { e-mail, MMS, SMS) }\end{array}$ \\
\hline $\begin{array}{l}\text { Interactive } \\
\text { digital TV }\end{array}$ & - Chat & - Interactive broadcasts & - Mass e-mail \\
\hline Telephone & & - Interactive voice response & \\
\hline $\begin{array}{l}\text { Personal } \\
\text { visit }\end{array}$ & - Electronic detailing aid & $\begin{array}{l}\text { - Interactive programs on } \\
\text { laptop/mobile device }\end{array}$ & $\begin{array}{l}\text { - Static electronic content } \\
\text { on laptop/mobile device }\end{array}$ \\
\hline
\end{tabular}

Figure 1: Selected e-detailing approaches

A human-human interaction denotes an approach where a customer communicates directly with a representative from a pharmaceutical company. This may take place synchronously in real time (eg video conference, chat room) or asynchronously (eg e-mail correspondence). In the case of rule-based human-machine interaction, a customer interacts with a program which is able to respond to customer requirements on the basis of rules. An example is a product presentation on a website which contains different information depending on the specialist knowledge of the customer. With static human-machine interaction the information is not dependent on customer behaviour. Examples are product information on static websites or e-mail newsletters. These three types of interaction differ in terms of the flexibility of communication: the customer's scope for influencing the content of communication is greatest in the case of human-human interaction and virtually non-existent in the case of static human-machine interaction (users can only decide whether or not they wish to receive the information).

The listed communication channels internet PC, mobile devices (mobile telephones, personal digital assistants, pagers), interactive digital TV (IDTV), telephone and personal visit each support different forms of communication (synchronous communication in real time or time-delayed, asynchronous communication) and are also differentiated by their diffusion and availability among customers as well as by their mediarichness. ${ }^{12,13}$ Whereas the internet PC channel, for example, permits both synchronous (chat, video conference) and asynchronous (e-mail) forms of communication and, depending on equipment, the transmission of text, image, audio and animations, the conventional telephone channel is limited to synchronous communication with the 
transmission of audio information.

Activities which concentrate on better

support for a pharmaceutical

representative's personal visit to the customer require the least amount of adaptation on the part of the customer. In comparison with the other channels, the personal visit provides the best means of building up a personal relationship thanks to its large communication bandwidth. In this respect, however, e-detailing activities contribute little to resolving the problems of conventional detailing.

\section{Examples of existing e-detailing solutions}

Of the e-detailing approaches shown in Figure 1, the following five have established themselves alongside the static information on websites, particularly in the US market:

- Video detailing. Here, doctors communicate with the representatives of a pharmaceutical company using PCs with internet access, camera, sound card and microphone, and obtain advice on specific products, ask questions or call up additional information via a web interface. The major provider of video detailing solutions is the US company iPhysicianNet

(www.iPhysicianNet.com) whose customer base includes amongst others Bristol Myers Squibb, Merck, Pharmacia, Aventis and Novartis. iPysicianNet operates a videoconferencing platform financed by the pharmaceutical companies and provides doctors with a PC plus internet connection free of charge. In return, the doctors agree to take part in one video detailing session a month with each of the participating pharmaceutical companies. Video detailing comes closest to personal face-to-face interaction because of the high proportion of analogue communication elements (image, speech, etc). Its broad mediarichness makes this form of electronic interaction well suited to knowledge transfer where complex issues are involved. ${ }^{14}$
- Telephone co-browsing. As in the case of video detailing, telephone co-browsing entails real-time interaction between a pharmaceutical representative or call centre operative and a doctor, while the pharmaceutical representative has access to the doctor's PC by remote control. The doctor and the pharmaceutical representative can talk to one another via an internet-based telephone line (IP telephony) and view web-based content at the same time. In comparison with video detailing, this form of e-detailing occupies less communication bandwidth, but does not provide a picture of the interlocutor. Telephone co-browsing is used, for example, by Novartis in France.

- Scripted or virtual detailing. Here, doctors access web-based, interactive multimedia programs - a mixture of Flash-based online presentation and online training for a specific product. As a rule, the presentations last between four and eight minutes. Following the presentation, doctors usually have the possibility to call up additional information, order samples or contact a pharmaceutical representative. Solutions of this kind are provided by Lathian Systems (www.lathian.com), RxCentric (www.rxcentric.com) or Physicians Interactive (www.physiciansinteractive.com). They are used, for example, by Johnson\&Johnson, Amgen, Aventis, Novartis and GlaxoSmithKline. The attractiveness of scripted detailing solutions lies primarily in all day, every day access for doctors and low variable costs for the pharmaceutical company. This makes them particularly well suited wherever there is a need to address a broad customer base. The use of interactive intelligent programs for customer self-service increases the amount of time and attention the visitor devotes to the web offering in comparison with static web pages. ${ }^{15}$

- Interactive voice response. Interactive voice response (IVR) detailing is a form of scripted detailing which is based on the telephone rather than the internet channel. Customers receive spoken product presentations and can interact with the 
program by voice or by key entry (eg to order samples). Solutions of this type are, for example, supplied by Physicians Interactive.

- e-mail. Personalised e-mail messages (textbased or in HTML format with images), tailored to suit the interests of the recipient, can be used for product promotion either as a marketing tool in their own right or as an integral part of other e-detailing solutions. In conjunction with e-detailing, pharmaceutical companies frequently use emails (as a rule, with the consent of the recipients) to send out invitations to visit web-based e-detailing programs. An example of a company which supplies the concept, performs the e-mail campaign and measures its success is Aptilon (www.aptilon.com).

\section{E-DETAILING POTENTIAL BENEFITS AND CHALLENGES IN EUROPE}

In spite of the different potential benefits e-detailing has to offer, European pharmaceutical companies in particular find themselves confronted with a series of challenges when it comes to trying to exploit those potential benefits.

Table 1 lists the challenges in conventional detailing and the main potential benefits and challenges of edetailing in Europe as perceived by the interviewees. For reasons of confidentiality, the companies' names have been withheld.

\section{Potential benefits}

Studies on the quantitative effects of edetailing projects available to the general public have mostly been carried out or sponsored by solution providers and refer to the North American market.

Independently sourced data exist on the system from iPhysicianNet used at Novartis where pharmaceutical representatives conduct 13 details with the video detailing solution (versus eight conventional details) on a daily basis, and have been able to discuss 2.7 (versus 1.6) products in each case. The costs of a detail were reduced to US\$48 (versus US\$106). ${ }^{16}$ A study by the HyGro Group on the benefits of a scripted detailing program from Physicians Interactive, performed for a product already established in the market, showed an increase in the prescription rate from 3.2 to 9.8 per cent in four months with a test group, which took part in two e-detailing sessions. ${ }^{17}$ Sixty-eight per cent of the doctors taking part rated the e-detailing program as better than a conventional detailing session. For scripted detailing in the case of doctors with a high prescription potential, the HyRo Group calculated a return on investment of 480 per cent (increase in prescriptions measured in relation to the program-development costs).

For reasons of confidentiality, the interviews yielded very little quantitative information on the effects of e-detailing. The measured (or anticipated) qualitative benefits of e-detailing stated by the interviewees included lower detail costs compared with the conventional approach as well as various benefits associated with a novel electronic customer interaction channel:

- Lower detail costs. The absence of travelling, waiting time and, in part, personnel expenses, means that it costs less to present products using electronic channels. Depending on the e-detailing approach used, the Forrester Group ${ }^{18}$ calculated, for the USA, savings of between 25 and 90 per cent per product presentation compared with conventional detailing.

- Greater reach and interaction frequency. Doctors whose low prescription potential previously made visits an unprofitable proposition can now be addressed thanks to the lower costs involved. The flexibility of use and the greater depth of information can facilitate access to doctors who had previously rejected or limited visits from pharmaceutical representatives.

- More customer information and better 
Table 1: Summary of interview results

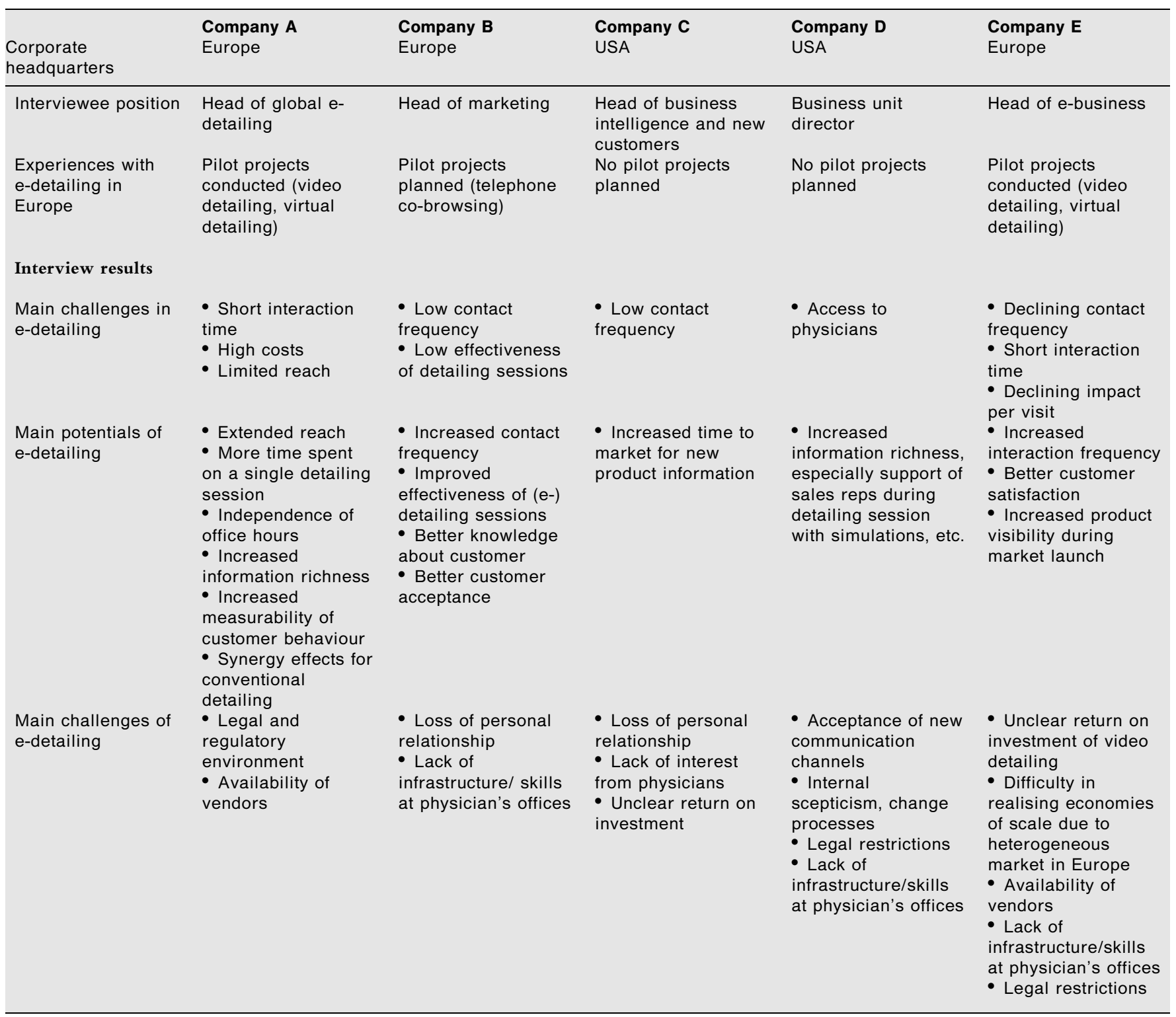

possibilities for classifying customers.

Electronic channels which incorporate a

facility for user identification provide a

source of additional information on

doctors' interests. If information on a

specific drug or area of therapy is accessed

on the doctor's own initiative, this allows

the pharmaceutical company to draw

farther-reaching conclusions about his or

her interests than when material is passively

received from a pharmaceutical

representative. In Europe, however, the evaluation and use of such information is restricted to a certain extent by data protection regulations.

- Synergy effects for conventional detailing. Edetailing is almost universally seen as a complement to conventional detailing rather than as a substitute for it. Examples where the potential for synergy exists include: obtaining customer information on one channel and using it on another; the pharmaceutical representative accessing content available on the internet when 
calling on doctors; or generally increasing the frequency of contacts between pharmaceutical companies and doctors. Positive marketing effects have been measured in various pilot projects with combined customer communication using conventional and electronic channels.

- Higher customer acceptance. E-detailing solutions give doctors greater control over the time, place and content of the detail and allow them a more active role in obtaining information which actually interests them (information pull). Pharmaceutical companies hope that this will encourage greater openness towards the content communicated during the detail. Doctors appreciate the flexibility which e-detailing gives them and take advantage of what is has to offer, for example, access outside normal office hours. ${ }^{19}$

- Greater depth and speed of information. Edetailing provides scope for multimedia product presentations, which may be made available to doctors at any time via electronic channels, and scope for straightforward links to further electronic information and services.

\section{Challenges}

Pharmaceutical companies find themselves confronted with a series of challenges when it comes to exploiting the potential benefits of e-detailing. Setting up edetailing channels means burdening the marketing budget with additional expenditure, at least in the medium term, while various market factors as well human resistance make the profitable use of new interaction channels difficult.

- Reduction in absolute marketing costs. The experience gained in projects and the results of interviews conducted show that electronic e-detailing channels will not replace conventional detailing involving personal visits to doctors, at least in the immediate future. Neither doctors nor pharmaceutical representatives want to go without personal face-to-face contact, and e-detailing activities run alongside traditional field visits. Therefore, contrary to ambitious expectations in the industry, ${ }^{20}$ e-detailing activities will not reduce a pharmaceutical company's marketing and sales expenditure in the near future.

- Provider situation and market structure. Until now, the providers of e-detailing solutions and platforms have concentrated on the North American market. It is only recently that the appropriate solutions have become available in Europe. ${ }^{21}$ The very heterogeneous structure of the European market in comparison with that in the USA adds an extra complication. The linguistic and cultural differences between the various regions in Europe limit the scope for achieving economies of scale through the reuse of existing electronic services. $^{22}$

- Legal restrictions. Statutory requirements and industrial codes of practice limit the possibilities for compensating doctors for using e-detailing. Payment and sponsoring models of the kind widely used in the USA are not transferable to Europe, which is why any profitability figures relating to edetailing from the USA are not very meaningful here. European companies face the challenge of finding alternative incentives which will encourage doctors to use their solutions. Differences are again to be found in the area of data protection it is difficult for European companies to collect and evaluate certain personal information; in some situations they may only do so with the express consent of the doctors concerned.

- Internal scepticism and resistance. Field sales play an important role in most pharmaceutical companies and consequently wield a corresponding level of influence within the organisation. Fears related to job losses or unwelcome changes in working practices can cause resistance to new detailing solutions to build up either consciously or subconsciously in field sales, thus hindering any projects in this area.

- Mistrust/objectivity of information. More and more doctors have access to the internet and use it to search for medical information. ${ }^{23,24}$ Information provided by pharmaceutical companies, however, is 
frequently regarded with scepticism. According to a study by Forrester, ${ }^{25}$ company-owned pharmaceutical websites rank bottom in the list of information sources used by doctors and considered to be valuable. Moreover, online information in general fails to rate as well as its offline equivalents. Doctors frequently state that they regard colleagues, medical books or journals as more independent and more significant for their own information requirements and for helping them to form opinions.

- Establishment/acceptance of new communication channels. The more complex forms of interaction such as video conferencing or telephone co-browsing require participants to take time to familiarise themselves with the technical environment as well as with the features and possibilities of electronic communication. ${ }^{26,27}$ The experience gained in e-detailing projects shows that confronting users with new and unfamiliar communication channels presents an initial barrier, which pharmaceutical companies have to overcome proactively (such as by providing user training). In addition, most European physicians are currently lacking the necessary infrastructure for certain edetailing approaches such as video detailing (PC with video camera and broadband internet access).

Table 2 summarises the main potential benefits and challenges identified in connection with e-detailing.

\section{CONCLUSIONS FOR PHARMACEUTICAL COMPANIES IN EUROPE}

\author{
E-detailing will complement rather than \\ replace conventional detailing. As a \\ consequence, future-oriented marketing in the \\ pharmaceutical industry requires coordinated \\ online and offline channels.
}

The main potential benefits of e-detailing are not to be found in the reduction of absolute marketing costs but in enhanced customer acquisition, selection and retention. In order to realise these potential benefits, pharmaceutical companies should ensure that they obtain valuable customer information via the electronic channels and also utilise it for all the other customer interaction channels.

Pharmaceutical companies should combine push and pull approaches when establishing edetailing channels. However, the European market is not yet ready for video detailing. Experience has shown that the initiative for establishing contact between pharmaceutical companies and doctors also has to come from the former in the case of e-detailing. ${ }^{28}$ A mix of different push or pull approaches (such as a combination of e-mail newsletter and scripted detailing) can therefore be useful. Now, however, the video detailing approach would not be a viable option for most regions in Europe, due to a lack of collaboration platform providers such as those to be found in the USA, for example with iPhysicianNet,

Table 2: Potentials and challenges of e-detailing

\begin{tabular}{|c|c|c|}
\hline & Benefit potentials & Challenges \\
\hline $\begin{array}{l}\text { Pharmaceutical } \\
\text { companies }\end{array}$ & $\begin{array}{l}\text { Lower detail costs } \\
\text { Greater reach and interaction frequency } \\
\text { More customer information and better } \\
\text { possibilities for classifying customers }\end{array}$ & $\begin{array}{l}\text { Reduction in absolute marketing costs } \\
\text { Provider situation and market structure } \\
\text { Legal restrictions }\end{array}$ \\
\hline & Synergy effects for conventional detailing & Internal scepticism and resistance \\
\hline Doctors & $\begin{array}{l}\text { Higher customer acceptance } \\
\text { Greater depth and speed of information }\end{array}$ & $\begin{array}{l}\text { Mistrust/objectivity of information } \\
\text { Establishment/acceptance of new } \\
\text { communication channels }\end{array}$ \\
\hline
\end{tabular}


and an inability to meet the high demands in terms of hardware infrastructure and communication bandwidth. Depending on the complexity of the interaction channel and the existing knowledge of the target customer group, users may require training in use of the technology.

Companies have to decide on their channel mix based on different marketing and productrelated factors as well as customer needs and preferences.

The choice of channel mix depends on factors such as target customer segment, marketing goals, and product importance, complexity and lifecycle phase. For this reason, many pharmaceutical companies have carried out or are carrying out tests to evaluate different combinations of products, target customers, e-detailing approaches and services. The activities observed mainly focus on the area of products with relatively high sales potential. In the early phases of the lifecycle of pharmaceutical products, edetailing seems to meet with a higher level of acceptance among doctors as interest in and need for information is greater here than in the case of established products. ${ }^{29,30}$ Ultimately, however, the factors which determine success are the doctors' channel preferences and their willingness to adopt new technology.

While product information is essential, it is hardly going to be enough to motivate doctors to use e-detailing facilities. Pharmaceutical companies have to think of effective incentives for the use of e-detailing channels, such as a broader spectrum of services that support the doctors' business processes.

The provision of effective incentive systems is a major challenge for e-detailing projects in Europe. The types of electronic interaction with the pharmaceutical company should therefore be expanded beyond straightforward product promotion to offer a broader spectrum of services and incentives geared to the doctors' customer process. The attractiveness of using such facilities can be enhanced, for example, by realising portalbased collaboration scenarios offering greater support for doctor-patientpharmaceutical company interaction, and thus ensuring that these services become more firmly embedded in doctors' day-today work processes.

The implementation of e-detailing requires coordinated change management.

Successful project implementation calls for support both at management level and at the level of the pharmaceutical representatives. The latter play a crucial role in making doctors aware of the electronic services available. The management of change, open communication of the potential benefits and impacts of e-detailing activities and continuous measurement of success are therefore important factors which will decide the success of a project.

Integrated IT systems are a prerequisite for coordinated online and offline activities. Pharmaceutical companies have to integrate e-detailing channels in their CRM system landscape.

Online and offline activities have to be coordinated and integrated, which requires a suitable level of integration where the information systems involved are concerned (eg customer relationship and/or territory management systems, content management systems, etc).

\section{References}

1 Senger, E. and Österle, H. (2002) 'PROMET BECS A project method for business engineering case studies', Institute of Information Management, University of St Gallen.

2 Bates, A., Bailey, E. and Rajyaguru, I. (2002) 'Navigating the e-detailing maze', International Journal of Medical Marketing, 2/3, 255-262.

3 Piper, M., Wandschneider, U. and Lerer, L. (2002) 'The future of customer focus and customer value in the pharmaceutical industry', INSEAD/Andersen. 
4 Elling, M.E., Fogle, H.J., McKhann, C.S. and Chris, S. (2002) 'Making more of pharma's sales force', The McKinsey Quarterly, 3

5 Jost, A. (1998) 'Computer aided selling im pharmakundenmanagement', Deutscher Universitäts-Verlag, Wiesbaden.

6 Bernewitz, T. (2001) 'E-detailing: Where does it fit in pharmaceutical sales?', ZS Associates.

7 Birlenbach, S., André, G., Palenberg, M., de Bertier, A. and Mauchard, P. (2001) 'E-detailing in Europe: Now or never?', In Vivo: The Business \& Medicine Report, 19(11), 69-79.

8 Elling, M.E. et al. (2002) op. cit.

9 Junger, D. (2001) 'e-detailing: The future of the primary care salesforce?', at Pharm.com, http:// www.inpharm.com/netfocus/news/viewpoints/ view_035.html.

10 Ibid.

11 Bernewitz, T. (2001) op. cit.

12 Daft, R.L. and Lengel, R.H. (1986) 'Organizational information requirements, media richness and structural design', Management Science, 32(5), 545-571.

13 Rice, R.E. (1992) 'Task analyzability, use of new media, and effectiveness: a multi-site exploration of media richness', Organization Science, 3(4), 475-500.

14 Senger, E., Gronover, S. and Riempp, G. (2002)

'Customer web interaction: Fundamentals and decision tree', Proceedings of Eighth Americas Conference on Information Systems, Dallas, 1966-1976.

15 Ibid.

16 Junger, D. (2001) op. cit.
17 Gleason, M. (2001) 'Internet detailing opens the doctor's door', Medical Marketing \& Media, January.

18 Boehm, E.W., Brown, E.G. and Molvar, K. (2001) 'Pharma's detailing overhaul', Forrester, Cambridge, $\mathrm{CA}$

19 Junger, D. (2001) op. cit.

20 Armstrong, L., Hill, S., Lerer, L., McDonald, J., Nechvatal, G., Parmar, B. et al. (2001) 'Vision and reality: The quantum shuffle - the impact of e on pharmaceutical and medical device industries', Cap Geminy Ernst \& Young, INSEAD.

21 Boehm, E.W., Holmes, B. J. and Twist, A. E. (2002) 'Pharmaceutical eDetailing takes root in Europe', Forrester, Cambridge, CA.

22 Birlenbach S., et al. (2001) op. cit.

23 Tyer, D. (2002) 'E-detailing: Trialling at a screen near you', at Pharmafocus.com, http:// www.pharmafile.com/pharmafocus/Features/ feature.asp?fID $=271$.

24 Boehm, E.W., Holmes, B.J. and Twist, A.E. (2002) op. cit.

25 Boehm, E.W., Brown, E.G. and Molvar, K. (2001) op. cit.

26 Sauer, J., Schramme, S. and Rüttinger, B. (2000) 'Knowledge acquisition in ecological product design: The effects of computer-mediated communication and elicitation method', Behavior \& Information Technology, 19(5), 315-327.

27 Tyer, D. (2002) op. cit.

28 Ibid.

29 Bernewitz, T. (2001) op. cit.

30 Tyer D. (2002) op. cit. 
Copyright $\odot 2003$ EBSCO Publishing 